\title{
HOMOGRAFT BONE IN REVISION ACETABULAR ARTHROPLASTY
}

\author{
A CLINICAL AND RADIOGRAPHIC STUDY \\ K. M. SAMUELSON, M. A. R. FREEMAN, B. LEVACK, G. L. RASSMUSSEN, P. A. REVELL \\ From LDS Hospital, Salt Lake City, and The London Hospital, London
}

\begin{abstract}
Thirty-seven patients with extensive acetabular defects due to loose implants had revisions with uncemented components, the acetabulum being augmented with homograft bone. In six of these, a histological study of graft incorporation was made. At a mean follow-up of 1.5 years 34 patients were free of pain and 35 could walk for $\mathbf{3 0}$ minutes or longer. No graft had obviously sequestrated. Two components had radiological evidence of migration but remain asymptomatic.

We conclude that cementless revision surgery with homograft supplementation of the acetabulum is clinically successful in the short-term. The long-term outcome is unknown.
\end{abstract}

Reconstruction after failure of the acetabular component is often difficult because of the size of the pelvic bone defect. This loss of bone comes about in four stages: the original arthritic process destroys bone; the initial reconstruction involves the removal of further bone by reaming or the making of keying-holes for cement; the acetabulum fails by upward migration, slowly destroying the bone as it does so; and the loose component, especially if this results in debris formation (of cement or polyethylene), may cause substantial osteolysis. As a consequence the acetabulum becomes enlarged and its walls thin. Although this cavity can be filled with polymethylmethacrylate cement (PMMA) and some suitable combination of a metal support ring and a polyethylene component, this does nothing to restore the amount of bone available to support load in the future. As a consequence, it is difficult to have confidence in the long-term integrity of such a reconstruction, a view supported by the reported clinical results of revision arthroplasty (Amstutz et al. 1982; Pellicci et al. 1982; Callaghan et al. 1985).

Bone autografts have been used to contribute to reconstruction of the acetabulum for years (Harris, Crothers and $\mathrm{Oh}$ 1977). In particular they have been used in the dysplastic acetabulum to reform the superior lip.

K. M. Samuelson, MD, Orthopaedic Surgeon

G. L. Rassmussen, MD, Orthopaedic Surgeon LDS Hospital, Salt Lake City, Utah, USA.

M. A. R. Freeman, MD, FRCS, Consultant Orthopaedic Surgeon B. Levack, FRCS, Senior Orthopaedic Registrar

P. A. Revell, PhD, FRCPath, Reader in Pathology

The London Hospital, Whitechapel, London El IBB, England.

Correspondence should be sent to Mr M. A. R. Freeman.

(C) 1988 British Editorial Society of Bone and Joint Surgery

0301-620X/88/3096 \$2.00

J Bone Joint Surg [Br] 1988;70-B:367-72.
Unfortunately, in the context of revision arthroplasty, large quantities of autogenous bone are difficult to obtain : the femoral head will already have been removed and many of these patients either have inflammatory joint disease or are elderly so that the cancellous bone in the ipsilateral ilium is porotic. The operating time involved and the magnitude of the surgical trauma make it difficult or unattractive to embark on two-stage procedures, taking bone from a remote site in the first stage and using it as a graft in the second. For these reasons it would be attractive, were it possible and clinically successful, to use homograft bone taken from a suitable bank.

Unfortunately the literature does not provide a secure basis for predicting the outcome of such a procedure. The clinical fate of bone homografts has been variously reported as successful or unsuccessful (Gregory 1972; Brown, Malinin and Davis 1976; Rish, McFadden and Penix 1976; Enneking, Eady and Burchardt 1980; Malinin and Brown 1981; Burchardt 1983; Borja and Mnaymneh 1985; Gross et al. 1985; Makley 1985). Very little information is available concerning the histological fate of bone homografts in man (Mankin and Friedlaender 1983). Studies based on radiological assessment of the graft are also few in number and the interpretation of the plain radiographs after procedures of this kind is difficult (Mjöberg et al. 1985; Chafetz et al. 1985). In general, however, it appears to be at least possible that cancellous homografts in man will incorporate into the pelvis, probably by a process of creeping substitution with the donor cells playing no part in the process, so that the graft can be thought of simply as a mechanical filler which, in conjunction with host tissues, has some capacity to become converted into living bone (Chase and Herndon 1955; Heiple, Chase and Herndon 1963; 
Goldberg and Lance 1972). It seems possible that the presence of autologous marrow within the donor material may promote this process (Burwell 1964).

It would seem in some ways counter-productive to combine the use of PMMA cement with such a bone graft, especially if the latter is used in the form of fine chips or a paste: the PMMA will diminish the amount of graft that can be inserted to reconstitute the skeleton. Fixation by cement to the graft material will not promote initial fixation of the implant since at this stage the graft itself is not incorporated into the pelvis. Injection of cement into the graft mass could be expected to prevent revascularisation and thus incorporation of the graft. We therefore felt that the use of bone grafts to reconstruct the acetabulum might best be postponed until a technique for cementless fixation had been developed and had proved effective for primary arthroplasty. We (Freeman et al. 1986) and others (Ring 1983; Morscher and Dick 1984; Bertin et al. 1985) have used such a technique with short-term clinical results equivalent both in terms of symptomatic relief and the loosening rate to cemented arthroplasty (Freeman et al. 1984). We have now extended this procedure in conjunction with bone grafting to the acetabulum requiring revision. Other authors have reported satisfactory early results using similar techniques with homograft bone (Sloof et al. 1984: McGann, Mankin and Harris 1986; Trancik et al. 1986).

We now report the combined experience obtained in LDS Hospital, Salt Lake City (KMS) and The London Hospital (MARF) using homografts and cementless acetabular fixation to reconstruct the bone-deficient acetabulum after aseptic loosening of a previous arthroplasty.

\section{MATERIALS AND METHODS}

Clinical study. Thirty-seven patients were included in the study and comprised 26 women and 11 men, with a mean age of 52 years (range 26 to 77 years) and a mean followup of 1.5 years (range 1 to 3 years). The pathology prior to the initial hip replacement was osteoarthritis in 31 patients, rheumatoid arthritis in four, while two patients had previous subcapital fractures. In 19 hips there had previously been a cemented stemmed implant, 13 hips were revised from cemented surface replacements and five were revised from cup arthroplasties.

All patients were seen and assessed pre-operatively, at six months after operation and at yearly intervals thereafter. A standard data sheet was completed recording pain (graded as absent, mild, i.e., occasional discomfort not requiring analgesia, moderate, i.e., pain requiring but controlled by simple analgesia, and severe), the total range of movement, and walking distance in minutes. The data were stored and analysed on a computer.

Radiographic study. Radiographs were taken 10 days after operation to form a basis for comparison with subsequent radiographs taken at six weeks, six months, one year and thereafter at yearly intervals. Qualitatively the appearance of the graft was assessed with respect to its density, the appearance of the graft-host junction, the appearance or absence of trabeculation within the graft, the position of the screws holding the prosthesis in place, and the height of the graft. Acetabular migration was assessed by drawing a horizontal line at the level of the "tear drops". A vertical line was then drawn through the centre of the "tear drop" on the replaced side. The centre of the femoral head was located and the distance in millimetres from this point to the horizontal and vertical lines was recorded. Because of projection differences and measurement error only a change of $5 \mathrm{~mm}$ or more was considered significant (Sutherland et al. 1982).

Operative technique. During a trial reduction with a "phantom"acetabular component, the appropriate size and position of the prosthesis is chosen so as to stabilise the hip and fill the acetabular cavity as far as possible. The prosthesis always rests, at least in part, on living bone in the acetabulum and thus has some intrinsic stability even without graft and screws. The prosthesis used is the Freeman support ring and polyethylene liner held with AO cancellous and cortical screws (Fig. 1).

Defects external to the support ring within the acetabular cavity are packed with morsellised homograft to which has been added fragments of autogenous bone and such marrow tissue as can be obtained from the femoral shaft. Graft is packed into all medial cavities and compressed with the aid of the "phantom" acetabular component. Defects in the mouth of the acetabulum are filled with a block of bone. The support ring is then fixed to the pelvis with up to six screws positioned as a ring around the mouth of the implant (Figs 2 and 3).

A support ring used in this way serves four functions: it provides initial compression of the graft; it rigidly fixes the elements of the pelvis to each other (if there is a partial medial fracture); it fixes bone blocks in the mouth of the acetabulum to the remaining pelvis by transfixion with a screw; and it provides for load transmission into the mouth of the acetabulum rather than solely into the superomedial graft itself.

Using this technique, superior and medial defects may not be fully reconstituted because the support ring is positioned to rest on living bone somewhere over its circumference. Thus the acetabular component is sometimes placed high or medial relative to its "ideal" anatomical position. The amount of graft bone required varies but is sometimes as much as two morsellised femoral heads distributed as a paste, ideally nowhere more than $1 \mathrm{~cm}$ distant from living bone.

Technique of obtaining homograft. Bone is taken from patients undergoing hip replacement or hemiarthroplasty for femoral neck fracture. Donors are screened for Australia antigen and cytomegalovirus. The bone is swabbed for bacteriological culture, triple wrapped in 


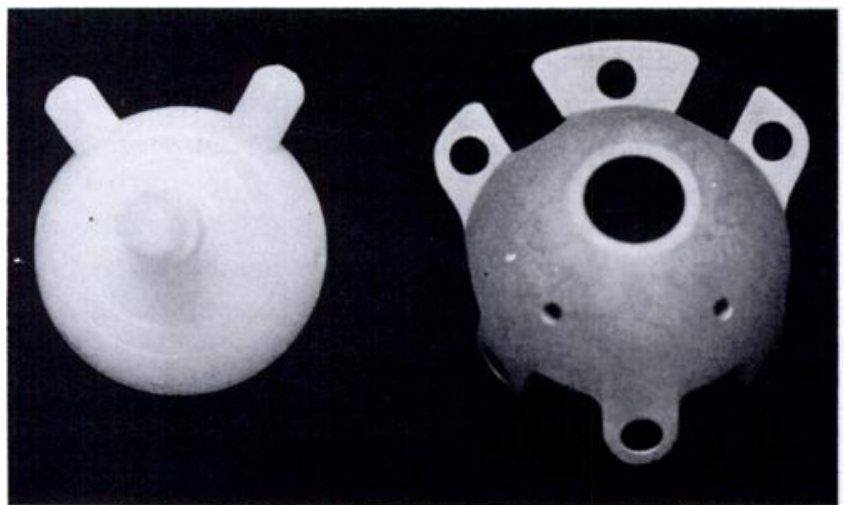

Fig. 1

Polyethylene liner (left) and support ring (right).

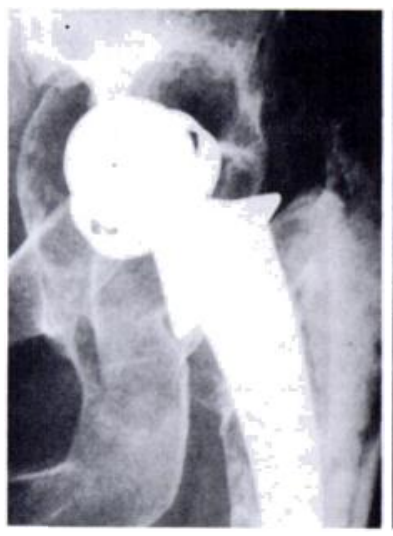

Fig. 2

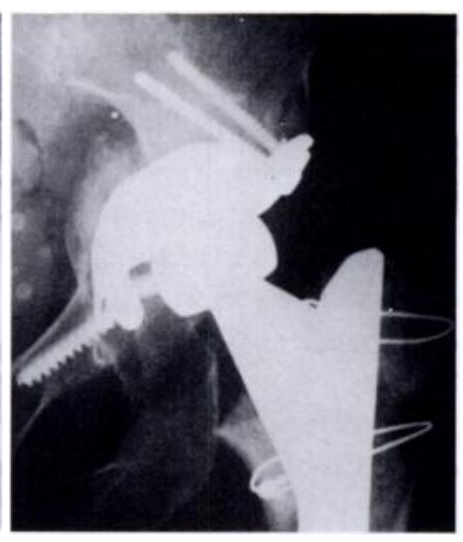

Fig. 3
Radiographs of the hip before and one year after revision.

steriie conditions and then frozen at $-70^{\circ}$ in its original moist state. Immediately prior to use the bone is thawed and again cultured.

\section{Clinical results}

\section{RESULTS}

Pain. Thirty-four patients were free of pain at review. Three patients had occasional pain sufficient to require analgesia or occasionally to prevent sleep: in one case the pain was thought to arise from the lumbosacral spine; in the other two the cause was unknown.

Range of movement. Thirty-four patients had a composite range of movement of more than $140^{\circ}$; this was the sum of flexion-extension, abduction-adduction and mediallateral rotation. Three patients had a composite range of less than $140^{\circ}$ but in each case this was an improvement on the pre-operative range: two of these patients suffered from juvenile rheumatoid arthritis.

Walking distance. Thirty-five patients could walk for periods longer than 30 minutes. Two patients could only walk for 15 and 20 minutes, but both had severe juvenile rheumatoid arthritis with multiple joint involvement; they were not the patients with residual pain.

\section{Radiography}

At the last review two patients were found to have superomedial migration of the acetabulum measuring $5 \mathrm{~mm}$ and $10 \mathrm{~mm}$ respectively; in both it was asymptomatic*. No other grafts had lost height and no other components appeared to have changed position (Figs 2 and 3). No graft had become more dense nor obviously sequestrated. In one case there was a lucent line between the graft and the host bone; in the remainder no line was visible. One screw had broken and one screw had backed out. In only one case was there unequivocal trabecular continuity between graft and host. The cardinal feature was the absence of any definite radiographic change in the graft from immediately after operation until the latest follow-up examination, an average of 1.5 years later.

\section{DISCUSSION}

We believe that there is, at least theoretically, a case for the use of homografts in reconstructing acetabula after failed total joint replacement. If after removal of the previous implant there is good bone stock in the pelvis and the patient is elderly, it may be best to fix a second prosthesis with cement. If the bone is severely destroyed so that cemented fixation of the second implant appears impractical, but the patient is elderly, consideration should be given to an excision arthroplasty. However, when the patient is younger every attempt should, in our view, be made to reconstruct the bony stock of the pelvis by the use of autografts if possible or, if the volume of the defect is such as to make this impractical, by the use of homografts. Because this clinical situation is unfortunately not rare, the fate of homografts used in this way and the development of an appropriate technique for their use have become subjects of practical interest hence our study.

We believe that our histological experience (see Appendix) represents the only study of its kind in the literature and, encouragingly, it shows that homograft incorporation in the pelvis in man proceeds in the same way and at the same rate as does (dead) autograft incorporation. This suggests that homografts might be clinically useful.

Clinically, the period of follow-up in our study is insufficient to allow us to draw any conclusion about long-term results, but the early clinical outcome is satisfactory. Morscher and Dick (1984), Ring (1983) and Bertin et al. (1985) have reported satisfactory results of cementless acetabular fixation with long-term follow-up and it may therefore be that these early results will be maintained in future.

The assessment of migration of acetabular compon-

* Since this paper was submitted for publication, the second of these two patients has become symptomatic and has had a revision operation. Before this it was known that the patient had had tuberculosis of the spine but this was thought to be inactive. At the revision, the hip was found to be the seat of a tuberculous infection presumed to be metastatic from the spine. Thus migration in this case may have been secondary to the infection. 
ents on two-dimensional radiographs which are not rigidly standardised is difficult in the absence of fixed markers in the pelvis or the use of Cartesian coordinates: Chafetz et al. (1985) have concluded that the interpretation of radiographs with conventional techniques is "subjective and unreliable". However, within the limits of the method used, only two acetabular components were seen to migrate, none had become obviously loose and no radiographic changes consistent with graft rejection were noted. Thus we have been unable to demonstrate loosening of the acetabular component or obvious migration in 35 of 37 implants.

In discussing the clinical and radiographic results, two questions need to be addressed:

1. What form does failure of the graft take?

2. For how long must patients be reviewed before failure of the reconstruction can be excluded?

In view of the limited experience with bone homografts in the acetabulum, both questions are difficult to answer. Thus McGann et al. (1986), reporting five cases of homografts at the hip with a minimum of two years' follow-up, commented on "the substantial uncertainties in the long-term outlook". Radiographically, bone graft failure might manifest itself as fatigue fracture, nonunion at the graft-host junction and graft resorption. It seems likely that such complications occurring about an extensively grafted acetabulum under load would result in early migration with loosening of the acetabular component and pain about the hip. With regard to the time which might elapse before these complications become manifest, Burchardt (1983), in a study of homografts in dogs, noted that cortical grafts after an early loss of bone density regained their initial strength in the second year after grafting; he correlated this with clinical data, recording a high incidence of fatigue fracture in the first 6 to 12 months after grafting. Thus radiographic, and perhaps symptomatic, failure of the graft in man might be expected to occur in the first year.

The clinical fate of our patients indicates that the methods that we have used to fix an acetabular prosthesis to the pelvis in the presence of a homograft will certainly provide adequate fixation for the first three months; our experimental study shows that this is the period during which the homograft might be incorporating. Thus, "failure of the graft", as defined above, was not observed in this period. After presumed graft incorporation the fate of the reconstructed acetabulum would depend upon the fate of cementless press-fitted acetabular components and upon the late behaviour of the graft as it consolidates. The symptomatic state of our patients at one to two years after operation combined with our finding that only two acetabular components had by then migrated, suggests but does not prove that the grafts, having become incorporated, are capable of supporting load and that the acetabular press-fit technique which we employed provides adequate fixation. The latter implication is supported by experience with this technique in hips in which homografts are not employed (Ring 1983; Freeman et al. 1984; Morscher and Dick 1984). Even if these acetabular reconstructions could be shown to function for five years, the long-term outcome would still be uncertain since most forms of acetabular replacement have been shown to function well for this period, only to fail with increasing frequency thereafter.

It might be expected that radiographic scrutiny of the graft area at intervals after operation would permit a clear description of the fate of the grafts and would form a basis for determining whether or not they had become incorporated. Unfortunately, practical considerations make this difficult. Thus the implant is metallic and obscures much of the graft in an ordinary anteroposterior radiograph. Other views of the pelvis are difficult to obtain with sufficient clarity of the graft area to make possible a definite statement about the graft. Even when the graft is visible on an anteroposterior view above the metallic prosthesis, detail is often obscured by the sclerotic bone in the living pelvis anterior and posterior to the graft area. Our observations suggest that the bone of the graft remains at least unchanged and perhaps becomes radiographically incorporated with the rest of the pelvis.

In summary, we believe our results suggest that homograft bone is capable of becoming clinically incorporated into the living human pelvis. When such bone is used to fill defects at the site of the failed acetabular replacement a reconstruction can be achieved which not only restores function to the hip but which also augments the amount of bone in the pelvis. We consider that both these objectives are of importance when reconstructing the failed young adult hip.

\section{APPENDIX}

\section{A QUANTITATIVE AND QUALITATIVE HISTOLOGICAL STUDY OF BONE GRAFT INCORPORATION IN MAN}

The histological results of bone grafting in man are not well described (Mankin and Friedlaender 1983). We therefore carried out a parallel experimental study in which we compared the histological appearance and rate of appositional new bone formation in relation to autograft bone, homograft bone and a composite mixture of the two when transplanted into the iliac crest of man.

Materials. The patients in this experimental study were six of the 37 patients undergoing cementless revision surgery with homograft acetabular augmentation described in the clinical study. All patients gave informed consent and the study had full approval of the ethical committee. There were four women and two men with an age range of 45 to 65 and a mean of 52 years.

The homograft bone used in the experimental study (derived from the London Hospital Bone Bank) was of the same type as used to augment the acetabulum. It was therefore known to be bacteriologically sterile. 
Method. At the time of hip replacement with homograft acetabular supplementation, and under the same general anaesthetic, a polyethylene peg $4 \mathrm{~cm}$ long was inserted into a pre-drilled hole in the iliac crest. In each peg were three transversely drilled holes of $0.4 \mathrm{~cm}$ diameter into which were packed homograft bone, autograft bone or a 50:50 mixture of the two.

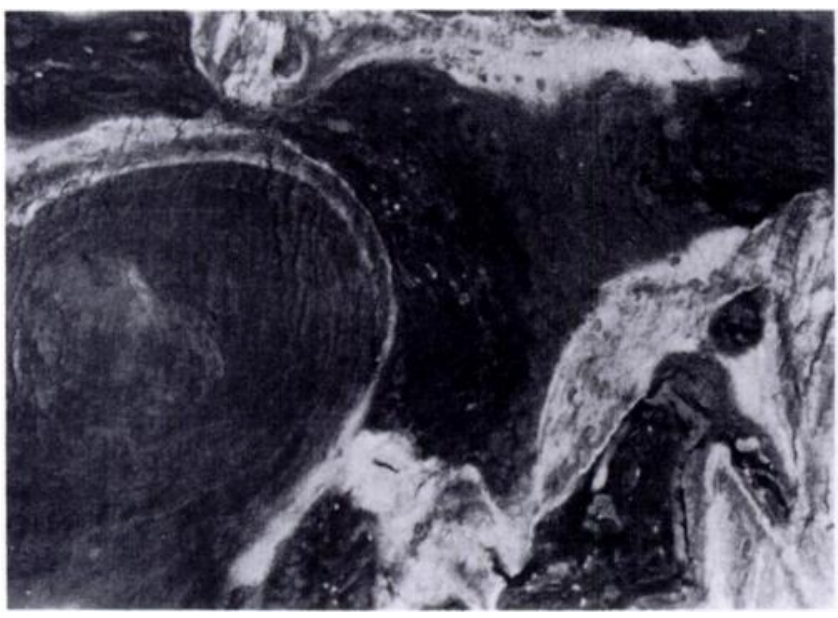

Fig. 4

High-power photograph of bone viewed by ultra-violet light microscopy demonstrating double labelling with tetracycline around the graft (bottom left). At the bottom right, a further bone graft with fluorescent tetracycline-labelled bone is seen, most of which is woven bone (which is also seen at the top).

Six weeks after operation the peg, with a surrounding ring of bone, was removed under local anaesthesia using a trephine. Two separate three-day courses of tetracycline ( $500 \mathrm{mg}$ four times a day) were given 21 and six days before removal of the peg to label the bone being mineralised at these times. The bone containing the peg was fixed in formalin, embedded in methylmethacrylate and sectioned (including the peg) without decalcification. Staining was by haematoxylin, eosin, thionine, and von Kossa methods for routine light microscopy.
Unstained sections were prepared for examination for tetracycline fluorescence by ultra-violet light microscopy.

The distance to which there was appositional new bone formation about the bone graft was measured using a calibrated eyepiece graticule. This measurement was made from both ends of each hole. When measurement was made using ultra-violet microscopy to visualise the fluorescent tetracycline double label, the rate of new bone formation could be calculated.

A similar experiment to this has previously been described in relation to autograft bone (Freeman, McLeod and Revell 1983).

Results. Light microscopical examination of the pegs containing bone grafts showed the same appearances in all six pegs. All the holes contained bone graft, seen as fragments of dead bone in fibrous tissue. In each of the outer thirds of the holes there was appositional new bone formation around the bone graft fragments together with new woven bone.

There was no evidence of new bone formation in the central part of the hole and the bone graft fragments sometimes showed the presence of surface osteoclasts resorbing the dead bone. No differences in histological appearance were noted between the reaction to homograft, autograft or homograft/autograft composite. The distance to which new bone formation extended from the periphery into each hole from either end was measured and mean values calculated for each type of graft in the six pegs available. New bone extended $2.04 \pm 0.89 \mathrm{~mm}$ in relation to homograft, $2.29 \pm 0.52 \mathrm{~mm}$ for homograft/autograft composite and $2.21 \pm 0.61 \mathrm{~mm}$ in relation to autograft bone. The difference in these values is not statistically significant.

Ultra-violet microscopy of unstained sections revealed deposition both of a diffuse fluorescent tetracycline in relation to woven bone and the double label where there was appositional new bone formation (Fig. 4). The mean apposition rate was $1.65 \pm 0.16 \mu \mathrm{m}$ per day for homograft, $1.84 \pm 0.23 \mu \mathrm{m}$ per day for homograft/autograft composite and $1.54 \pm 0.64 \mu \mathrm{m}$ per day for autograft. The healing bone around the peg showed new bone formation in apposition to already existing trabeculae; the appositional rate in this bone was $1.71 \pm 0.36 \mu \mathrm{m}$ per day. None of these values is statistically different from any of the others.

These data would suggest that at least in the first six weeks after transplantation, homograft bone incorporates at least as well as autograft bone or a composite mixture of the two.

No benefits in any form have been received or will be received from a commercial party related directly or indirectly to the subject of this article.

\section{REFERENCES}

Amstutz HC, Ma SM, Jinnah RH, Mai L. Revision of aseptic loose total hip arthroplasties. Clin Orthop 1982;170:21-33.

Bertin KC, Freeman MAR, Morscher E, Deri A, Ring PA. Cementless acetabular replacement using pegged polyethylene prosthesis. Arch Orth Trauma Surg. 1985;104:251-61.

Borja FJ, Mnaymneh W. Bone allografts in the salvage of difficult hip arthroplasties. Clin Orthop 1985;197:125-31.

Brown MD, Malinin TI, Davis PB. A roentgenographic evaluation of frozen allografts versus autografts in anterior cervical spinal fusions. Clin Orthop 1976;119:231-6.

Burchardt $H$. Biology of cortical bone graft incorporation. In: Friedlaender GE, Mankin HJ, Sell KW, eds. Osteochondral allografts: biology, banking and clinical applications. Boston, etc: Little Brown \& Co [1983]:51-7.

Burwell RG. Studies in transplantation of bone. VII. The fresh composite homograft-autograft of cancellous bone: an analysis of factors leading to osteogenesis in marrow transplants and in marrow-containing bone grafts. J Bone Joint Surg $[\mathrm{Br}]$ $1964: 46-B: 110-40$.
Callaghan JJ, Salvati EA, Pellicci PM, Wilson PD Jr, Ranawat CS. Results of revision for mechanical failure after cemented total hip replacement, 1979 to 1982: a two to five-year follow-up. J Bone Joint Surg [Am] 1985;67-A:1074-85.

Chafetz N, Baumrind S, Murray WR, Genart HK, Korn EL. Subsidence of the femoral prosthesis: a stereophotogrammetric evaluation. Clin Orthop 1985;201:60-7.

Chase SW, Herndon $\mathrm{CH}$. The fate of autogenous and homogenous bone grafts: a historical review. J Bone Joint Surg [Am] 1955;37-A :809-41.

Enneking WF, Eady JL, Burchardt H. Autogenous cortical bone grafts in the reconstruction of segmental skeletal defects. $J$ Bone Joint Surg [Am] 1980;62-A :1039-58.

Freeman MAR, McLeod H, Revell PA. Bone ingrowth and graft incorporation in polythene pegs in man. Transactions of the Orthopaedic Research Society 1983;8:133

Freeman MAR, Ring PA, Levai J-P, McLeod H. Cementless fixation of the acetabular component of the hip. $J$ Bone Joint Surg [Br] $1984 ; 66-B: 147-8$ 
Freeman MAR, Rasmussen GLC, Camargo JN, Bertin KC. Cementless fixation of prosthetic components in total hip arthroplasty. In: Selvik J, Goldie I, eds. The young patient with degenerative hip disease. Stockholm: Almqvist \& Wiksell International, 1986:281-93.

Goldberg V, Lance EM. Revascularization and accretion in transplantation: quantitative studies of the role of the allograft barrier. $J$ Bone Joint Surg [Am] 1972:54-A :807-16.

Gregory CF. The current status of bone and joint transplants. Clin Orthop 1972:87:165-6.

Gross AE, Lavoie MV, McDermott P, Marks P. The use of allograft bone in revision of total hip arthroplasty. Clin Orthop 1985;197:115-22.

Harris WH, Crothers O, Oh I. Total hip replacement and femoral-head bone-grafting for severe acetabular deficiency in adults. $J$ Bone Joint Surg [Am] 1977;59-A:752-9.

Heiple KG, Chase SW, Herndon CH. A comparative study of the healing process following different types of bone transplantation. $J$ Bone Joint Surg [Am] 1963;45-A:1593-612.

Makley JT. The use of allografts to reconstruct intercalary defects of long bones. Clin Orthop 1985;197:58-75.

Malinin TI, Brown MD. Bone allografts in spinal surgery. Clin Orthop $1981 ; 154: 68-73$

Mankin HJ, Friedlaender GE. Perspectives on bone allograft biology. In: Friedlaender GE, Mankin HJ, Sell KW, eds. Osteochondral allografts: biology, banking and clinical applications. Boston, etc: Little Brown \& Co [1983]:3-8
McGann W, Mankin HJ, Harris WH. Massive allografting for severe failed total hip replacement. J Bone Joint Surg [Am] $1986 ; 68-A: 4-12$.

Mjöberg B, Brismar J, Hansson LI, Pettersson H, Selvik G, Önnerfält R. Definition of endoprosthetic loosening: comparison of arthrography, scintigraphy and roentgen stereophotogrammetry in prosthetic hips. Acta Orthop Scand 1985;56:469-73.

Morscher E, Dick W. Cementless fixation of a polyethylene acetabular component. In: Morscher E, ed. The cementless fixation of hip endoprostheses. Berlin, etc: Springer-Verlag, 1984:200-4.

Pellicci PM, Wilson PD Jr, Sledge CB, Salvati EA, Ranawat CS, Poss R. Revision total hip arthroplasty. Clin Orthop 1982;170:34-41.

Ring PA. Uncemented acetabular replacement. Arch Orthop Trauma Surg 1983;101:225-9.

Rish BL, McFadden JT, Penix JO. Anterior cervical fusion using homologous bone grafts: a comparative study. Surg Neurol $1976 ; 5: 119-121$.

Slooff TJJH, Huiskes R, van Horn J, Lemmens AJ. Bone grafting in total hip replacement for acetabular protrusion. Acta Orthop Scand 1984;55:593-6.

Sutherland CJ, Wilde AH, Borden LS, Marks KE. A ten-year follow-up of one hundred consecutive Müller curved-stem total hipreplacement arthroplasties. J Bone Joint Surg [Am] $1982 ; 64-A: 970-82$.

Trancik TM, Stulberg BN, Wilde AH, Feiglin DH. Allograft reconstruction of the acetabulum during revision total hip arthroplasty: clinical, radiographic, and scintigraphic assessment of the results. $J$ Bone Joint Surg [Am] 1986;68-A:527-33. 